\title{
Progression to microalbuminuria in patients with type 1 diabetes: a seven-year prospective study
}

Roberta A Cobas ${ }^{1 *}$, Bráulio Santos ${ }^{2}$, Pedro CB da Silva ${ }^{1}$, Ricardo Neves ${ }^{3}$ and Marilia B Gomes ${ }^{1}$

\begin{abstract}
Background: The presence of microalbuminuria can be associated with overt nephropathy and cardiovascular disease in patients with type 1 diabetes (T1D). We aimed to determine the incidence and evaluate the baseline predictors for the development of microalbuminuria in patients with T1D.

Methods: This study is a longitudinal cohort study of 122 normoalbuminuric patients with T1D who were receiving routine clinical care at baseline. A detailed medical history was taken, and a physical examination was performed at baseline. All of the patients were regularly examined for diabetes-associated complications. An analysis of predictors was performed using the Cox regression.

Results: Over 6.81 (3.59-9.75) years of follow-up, 50 (41\%) of the patients developed microalbuminuria. The incidence density was 6.79/100 people per year (95\% Cl 5.04-8.95), and the microalbuminuria developed after 5.9 (2.44-7.76) and 11 (5-15) years of follow-up and diabetes duration, respectively. After an individual Cox regression, the baseline variables associated with the development of microalbuminuria were age, age at diagnosis, duration of diabetes, systolic and diastolic blood pressure, fasting glycemia, body mass index (BMI), total cholesterol and triglycerides levels, cholesterol/HDL ratio and a family history of type 2 diabetes.After a multivariate Cox regression, the only independent factors associated with the development of microalbuminuria were BMI [HR 1.12 (1.03-1.21)] and cholesterol/HDL ratio [HR 1.32 (1.05-1.67)].

Conclusions: A higher BMI and cholesterol/HDL ratio increased the risk of developing microalbuminuria in young patients with T1D after a short follow-up. Both risk factors are modifiable and should be identified early and followed closely.
\end{abstract}

Keywords: Diabetic Nephropathy, Microalbuminuria, Incidence, Risk Factors, Type 1 Diabetes

\section{Background}

Type 1 diabetes (T1D) leads to an increased risk of morbidity and early mortality due to chronic complications [1] affecting both the micro- and macrovasculature.

Diabetic nephropathy (DN) is one of the most serious chronic complications of T1D, affecting approximately $20-30 \%$ of patients and increasing the risk of cardiovascular disease [2] and end-stage renal disease [3].

Diabetic nephropathy consists of several stages. Early microalbuminuria is considered to be one of its most important predictors [4] and is also associated with the

\footnotetext{
* Correspondence: robertacobas@ig.com.br

${ }^{1}$ Division of Diabetes, Department of Medicine, State University of Rio de Janeiro, Rio de Janeiro, Brazil

Full list of author information is available at the end of the article
}

development of cardiovascular disease [5]. Furthermore, the progressive decline of renal function in patients with T1D is an early event that occurs in a large proportion of patients with microalbuminuria [6]. Metabolic and hemodynamic factors contribute to the development of diabetic nephropathy, probably by interacting with a genetic susceptibility $[7,8]$.

The aim of this longitudinal study was to determine the incidence of and predictors for the development of microalbuminuria in a sub-set of Brazilian patients with T1D.

\section{Methods}

We conducted a longitudinal observational study including outpatients with T1D who regularly attended the diabetes clinic at the University Hospital Pedro Ernesto, 
a tertiary referral hospital of the State University of Rio de Janeiro, Brazil. The inclusion criteria were a T1D diagnosis, regular follow-up at our clinic and agreement to participate by means of informed consent. Exclusion criteria were less than 2 follow-up visits, the presence of either incipient or clinical nephropathy at baseline and end-stage renal disease. The initial cohort started in January 1991 when 110 patients were invited to participate in a study of the complications of diabetes. Initially, 50 patients were enrolled in the protocol, and these data were published elsewhere [9]. A dynamic cohort analysis was then performed. During the follow-up, the patients were seen in our clinic and received routine clinical care.

All of the patients were regularly examined for complications of diabetes. At baseline, detailed medical histories were taken, and physical examinations were performed. The data of interest included gender, age, age at diagnosis of diabetes, first-degree family history of type 2 diabetes (T2D), duration of the disease and daily insulin dose. All of the participants provided three accurately overnight urine samples with an interval of at least one week between collections within a period of six months. The participants were instructed to collect urine under their usual conditions, avoiding intensive physical activity. The urine was collected into containers without preservatives. The urinary volume was recorded, and the aliquots were stored in glass tubes at $-20^{\circ} \mathrm{C}$ until analysis (within 2 months). Urinary albumin concentration was estimated using a solid-phase competitive chemiluminescent enzyme immunoassay (Immulite 1000 Systems, DPC Medlab, Los Angeles, CA, sensitivity of $0.9 \mu \mathrm{g} / \mathrm{ml}$ ) with intra-assay and inter-assay coefficients of variation of $2.4 \%$ and $5.7 \%$, respectively. The patients with albumin excretion rates (AER) of $<20 \mu \mathrm{g} / \mathrm{min}$ during the follow-up were classified as normoalbuminuric. Microalbuminuria was defined as an AER of $\geq 20$ and $<$ $200 \mu \mathrm{g} / \mathrm{min}$ in at least two out of three of the overnight urine specimens collected.

Each urine specimen was tested for the presence of urinary infections and if present, the urine was discarded, and a new sample was collected after treatment. Normal serum creatinine levels $(0.8-1.4 \mathrm{mg} / \mathrm{dl})$ and normal urinary sediments (absence of proteins, red blood cells, hemoglobin, white blood cells, nitrites and casts) were used to exclude primary renal disease.

Fasting blood samples were obtained on the same day as the overnight urine delivery. All of the patients were given their usual insulin doses after the fasting blood collection. Blood was collected two hours after the patients' usual breakfast for the assessment of postprandial glycemia.

Triglyceride, total cholesterol, high-density lipoprotein (HDL) cholesterol, fasting plasma glucose (FPG) and plasma creatinine levels were measured by an enzymatic procedure using an auto analyzer (Cobas - Mira Roche). Low-density lipoprotein (LDL) cholesterol levels were calculated using the Friedwald method[10]. Glycated hemoglobin (A 1c) levels were determined by HPLC (Hitachi L-9100) with reference range of $2.6 \%$ to $6.2 \%$.

An ophthalmologist examined all of the retinas by fundoscopy through dilated pupils using slit lamp stereoscopic biomicroscopy, and the patients were classified into two groups depending on the presence or absence of either nonproliferative or proliferative retinopathy. The more severely affected eye was used for the evaluation.

Blood pressure was measured 3 times after 5 minutes of rest in the supine position by the same observer using a standard mercury sphygmomanometer. The mean of these values was then calculated. Weight and height were measured to the nearest $0.1 \mathrm{Kg}$ and $0.1 \mathrm{~cm}$, respectively. Body mass index (BMI- $\left.\mathrm{Kg} / \mathrm{m}^{2}\right)$ was calculated, and the patients were classified into two groups (normal, BMI $<25 \mathrm{~kg} / \mathrm{m}^{2}$ for adults and $<85^{\text {th }}$ percentile for children and adolescents or overweight/obese, when higher values were obtained) [11].

The observational design was approved by the local ethics committee.

Numeric values are expressed as medians (interquartile ranges), and categorical variables are expressed as counts (percentages). The analysis was performed using the statistical package Stata version 10 software. Cox regression univariate analysis was performed on each baseline variable. The patients contributed until they developed microalbuminuria, and the outcome was defined as the time elapsed until the development of microalbuminuria. Cox's proportional hazards model was used to estimate the hazard ratios and 95\% confidence intervals. The variables were eligible to enter the multivariate model if the $\mathrm{p}<0.25$ in univariate Cox regression. The proportional hazards assumption was verified by analysis of the Schoenfeld residuals and assessment of a graph of the survival function versus the survival time. The incidence rate of microalbuminuria is expressed as cases/100 patients/year. Receiver operating characteristic (ROC) analysis was performed to identify the threshold value of the baseline AER that predicted the development of microalbuminuria.

\section{Results}

The baseline clinical data for all of the patients in the cohort analysis is presented in Table 1.

Over the 6.81 (3.59-9.75) years of follow-up, 50 (41\%) of the 122 normoalbuminuric patients at baseline fulfilled the criteria for microalbuminuria. This yielded an incidence density of $6.79 / 100$ people/year (95\% CI, 5.04-8.95).

The follow-up period and the duration of diabetes until the development of microalbuminuria were 5.9 
Table 1 Baseline characteristics of the patients with type 1 diabetes

\begin{tabular}{|c|c|c|c|}
\hline & Total & Microalbuminuric group & Normoalbuminuric group \\
\hline $\mathrm{N}$ & 122 & 50 & 72 \\
\hline Gender (Male) & $59(48.4)$ & $21(42.0)$ & $38(52,8)$ \\
\hline Age (years) & $17(12.0-25.2)$ & $20(14-26)$ & $14(9-21)$ \\
\hline Age at diagnosis (years) & $12(7.0-9.0)$ & $14(9-23)$ & $11(6-18)$ \\
\hline Duration of diabetes (years) & $3(1.0-5.6)$ & $4.0(2.0-8.3)$ & $2.0(1.0-4.5)$ \\
\hline Insulin dose (IU/Kg/day) & $0.7(0.46-0.99)$ & $0.73(0.59-1.12)$ & $0.63(0.44-0.98)$ \\
\hline Systolic blood pressure $(\mathrm{mmHg})$ & $103(97-110)$ & $103(100-110)$ & $104(97-110)$ \\
\hline Diastolic blood pressure $(\mathrm{mmHg})$ & $68(60-73)$ & $69(61-73)$ & $68(60-73)$ \\
\hline Fasting plasma glycemia (mg/dl) & $150(110-233)$ & $163(123-253)$ & $147(108-224)$ \\
\hline Two-hour post-prandial glycemia (mg/dl) & $221(148-312)$ & $229(148-345)$ & $214(149-306)$ \\
\hline A1c (\%) & $7.2(6.5-8.11)$ & $7.0(6.5-7.9)$ & $7.3(6.6-8.5)$ \\
\hline Total cholesterol level (mg/dl) & $158(140-191)$ & $164(143-197)$ & $157(138-183)$ \\
\hline Trygliceride level (mg/dl) & $60(46-81)$ & $68(50-97)$ & $55(44-73)$ \\
\hline HDL cholesterol level (mg/dl) & $49(41-57)$ & $49(42-56)$ & $48(39-63)$ \\
\hline LDL cholesterol level (mg/dl) & $105(86-137)$ & $113(92-14)$ & $101(83-121)$ \\
\hline Cholesterol/HDL ratio & $3.3(2.7-4.1)$ & $3.4(2.8-4.2)$ & $3.2(2.6-4.0)$ \\
\hline LDL/HDL ratio & $2.3(1.6-3.1)$ & $2.5(1.8-3.4)$ & $2.0(1.5-2.9)$ \\
\hline Plasma creatinine level (mg/dl) & $0.65(0.6-0.8)$ & $0.7(0.6-0.9)$ & $0.6(0.6-0.8)$ \\
\hline Albumin excretion rate $(\mu \mathrm{g} / \mathrm{min})$ & $7.0(4.3-10.2)$ & $7.4(5.1-11.5)$ & $6.8(4.1-10.0)$ \\
\hline BMI $\left(\mathrm{kg} / \mathrm{m}^{2}\right)$ & $20(18-22)$ & 20.7 (18.9 22.7) & $19.2(17.1-21)$ \\
\hline Overweight or obese & $22(18)$ & $8(16.0)$ & $14(19.4)$ \\
\hline Presence of retinopathy * & $6(5)$ & $2(4.1)$ & $4(5.6)$ \\
\hline Family history of type 2 diabetes** & $24(22)$ & $13(28,3)$ & $11(16,4)$ \\
\hline
\end{tabular}

Continuous variables are presented as median (interquartile range), and categorical variables are presented as $\mathrm{n}$ (\%).A1c, glycated hemoglobin; BMI, body mass index; HDL, high density lipoprotein; $L D L$, low density lipoprotein * 2 evaluations are missing ** Data from 8 subjects are missing

(2.44-7.76) and $11(5-15)$ years, respectively. The final AERs were 32.3 (22-50) $\mathrm{ug} / \mathrm{min}$ and 7.35 (4.95-11.6) ụg/ min for patients who had microalbuminuria and patients who had persistent normoalbuminuric,respectively.

The baseline AER did not significantly predict the development of microalbuminuria in the ROC analysis (AUC $=0.57,95 \%$ CI 0.46-0.67), and there was no single best threshold value.

The baseline variables that were selected to enter the multivariate proportional hazards regression were age, age at diagnosis, duration of diabetes, systolic blood pressure (sBP), diastolic blood pressure (dBP), FPG, BMI, total cholesterol and triglycerides levels, cholesterol/HDL and LDL/ HDL ratio and a family history of T2D.(Table 2).

After multivariate Cox regression, the independent factors that were associated with the development of microalbuminuria were BMI and cholesterol/HDL ratio (Table 2).

\section{Discussion}

In our prospective study of normoalbuminuric patients with juvenile-onset T1D, 41\% developed microalbuminuria after an 11-year duration of diabetes and 5.9 (2.44-
7.76) years of follow-up, resulting in a greater overall crude incidence and incidence density of microalbuminuria than those reported in other studies [2,12-17].

In addition to the most described predictors of the progression to diabetic nephropathy and AER levels in T1D, such as duration of diabetes $[11,18,19]$, blood pressure $[11,18,19]$ and lipid levels [18-20], the development of microalbuminuria in our population was determined by age, age at diagnosis, BMI, FPG and a family history of T2D.As previously reported[21,22],A1c did not predict the development of microalbuminuria in our population,which is in contrast to other reports[12-14,18,19].

In our study, the levels of AER at baseline also did not predict the development of microalbuminuria, which is in contrast to other studies where higher initial levels of AER predicted the progression to microalbuminuria $[13,14]$.

In addition to the classical risk factors, others may influence the development of microalbuminuria [23]. Considering the increasing frequency of weight gain and obesity in patients with T1D over the last decade, these clinical conditions that result in insulin resistance may be involved in the pathology of microalbuminuria [24]. 
Table 2 Cox proportional hazard model of baseline risk factors for development of microalbuminuria in 122 patients with type 1 diabetes who were followed for seven years

\begin{tabular}{|c|c|c|c|}
\hline \multirow{2}{*}{$\begin{array}{l}\text { Baseline Data } \\
\text { Age }\end{array}$} & \multicolumn{2}{|c|}{ Univariate Analysis Hazard Ratio $(95 \% \mathrm{Cl}) \mathrm{p}$ value } & Multivariate Model Hazard ratio $(95 \% \mathrm{Cl}) \mathrm{p}$ value \\
\hline & $1.03(1.00-1.06)$ & 0.026 & \\
\hline Age at diagnosis & $1.03(0.99-1.06)$ & 0.123 & \\
\hline Gender & $0.92(0.52-1.63)$ & 0.779 & \\
\hline Duration of diabetes & $1.03(0.98-1.07)$ & 0.247 & \\
\hline Insulin dose & $1.34(0.77-2.32)$ & 0.302 & \\
\hline AER & $1.01(0.96-1.07)$ & 0.660 & \\
\hline Systolic blood pressure & $1.02(0.99-1.04)$ & 0.170 & \\
\hline Diastolic blood pressure & $1.02(0.99-1.06)$ & 0.210 & \\
\hline A1c & $1.02(0.87-1.20)$ & 0.810 & \\
\hline Two-hour post-prandial glycemia & $0.99(0.99-1.00)$ & 0.294 & \\
\hline Fasting glycemia & $1.00(0.99-1.01)$ & 0.234 & \\
\hline BMI & $1.12(1.03-1.22)$ & 0.006 & $1.12(1.03-1.21)$ \\
\hline Total cholesterol level & $1.01(1.0-1.01)$ & 0.042 & \\
\hline HDL cholesterol level & $0.99(0.98-1.02)$ & 0.930 & \\
\hline Triglyceride level & $1.00(0.99-1.01)$ & 0.08 & \\
\hline LDL cholesterol level & $1.01(1.00-1.01)$ & 0.045 & \\
\hline Cholesterol/HDL ratio & $1.32(1.07-1.63)$ & 0.010 & $1.32(1.05-1.67)$ \\
\hline LDL/HDL ratio & $1.26(0.97-1.62)$ & 0.079 & \\
\hline Presence of retinopathy & $1.37(0.33-5.68)$ & 0.667 & \\
\hline Family history of type 2 diabetes & $2.03(1.06-3.92)$ & 0.044 & \\
\hline
\end{tabular}

BMI, body mass index; AER, albumin excretion rate; A1c, glycated hemoglobin; HDL, high density lipoprotein; LDL, low density lipoprotein

In our patients, most of who were young adults of a normal weight, the only independent factors associated with the development of microalbuminuria were BMI and the cholesterol/HDL ratio.

Intensive insulin treatment, although beneficial for decreasing the risk of diabetic complications, can result in weight gain [25]. The effects of weight gain may be intensified when not accompanied by good glycemic control. It has been postulated that a first-degree family history of T2D, already reported to be higher in Brazilian patients with T1D compared to non-diabetic patients [26], predisposes these patients to a higher risk of weight gain and insulin resistance.

The features of metabolic syndrome that are associated with insulin resistance, which tend to increase with disease progression [27], were found to be risk factors for overt nephropathy and renal injury $[13,14,28-31]$, due in part to low-grade inflammation and oxidative stress [32]. Patients with T1D can be more susceptible to LDL oxidation in vitro [33] and have higher levels of acute-phase proteins compared to non-diabetic subjects [34].

Higher levels of HDL were found to have a protective effect against the development of albuminuria in longstanding type 1 diabetic patients [35]. However, even when they had normal or slightly high plasma HDL cholesterol levels, type 1 diabetic patients were predisposed to the early development of atherosclerosis because of the loss of the ability of HDL to protect arteries from the inhibition of the endothelium-dependent relaxation induced by oxidized-LDL [36]. Total cholesterol [14] and LDL-cholesterol $[13,20]$ levels were also associated with the progression to microalbuminuria.

DN is also associated with cardiovascular disease [37], and dyslipidemia is considered a risk factor for both conditions [38]. In addition, cholesterol levels increase as DN progresses and also correlate positively with the rate of fall in the glomerular filtration rate[39].

It should be noted that we can intervene to mitigate many of these factors. However, the effects of these interventions in affording or delaying the onset of renal injury in these patients must be addressed. Furthermore, microalbuminuria reverts without specific treatment in a significant percentage of patients[40].

These facts are of great importance in deciding the proper time to initiate a specific treatment, particularly because most of the patients are young people of reproductive age.

The limitations of our study include the variable follow-up time and the high number of events. In fact, the final AER levels in those patients who progressed to 
microalbuminuria were close to the normal range of albuminuria, and this group may have included those patients who spontaneously revert to normoalbuminuria. Family history of hypertension was absent and ethnicity was difficult to characterize in the study population based on ectoscopy or self-report [41], so these data could not be evaluated as risk factors.

\section{Conclusions}

Higher BMIs and cholesterol/HDL ratios at a young age increased the risk of developing microalbuminuria in patients with juvenile-onset T1D after a short follow-up. Both risk factors are modifiable and should be identified early. We suggest that weight and lipid profiles must be followed closely in patients with T1D.

\section{List of Abbreviations}

AER: albumin excretion rate; BMl: body mass index; dBP: diastolic blood pressure; DN: diabetic nephropathy; FPG: fasting plasma glucose; sBP: systolic blood pressure; T1D: type 1 diabetes; T2D: type 2 diabetes

\section{Acknowledgements}

This study was supported by a grant from CNPq (Conselho Nacional de Desenvolvimento Científico e Tecnológico) process number 471014/2004 and FAPERJ (Fundação de Amparo à Pesquisa do Estado do Rio de Janeiro) process number e-26/102.203/2008. We gratefully thank Maria de Fátima Bevilacqua and Eliete Leão.

\section{Author details}

${ }^{1}$ Division of Diabetes, Department of Medicine, State University of Rio de Janeiro, Rio de Janeiro, Brazil. ${ }^{2}$ Biostatistics and Bioinformatics Unit, National Institute of Cardiology, Rio de Janeiro, Brazil. ${ }^{3}$ Division of Ophthalmology, Department of Medicine, State University of Rio de Janeiro, Rio de Janeiro, Brazil.

\section{Authors' contributions}

RAC participated in the design of the study, data collection, drafted the manuscript.PCBS participated in the collection of data and helped to draft the manuscript.RN conducted ophthalmologic evaluations, participated in the study design and helped to draft the manuscript. BS participated in the design of the study and performed statistical analysis.MBG participated in the design and coordination, helped to draft the manuscript and gave final approval.All authors read and approved the final manuscript.

\section{Competing interests}

The authors declare that they have no competing interests.

Received: 13 July 2011 Accepted: 26 August 2011

Published: 26 August 2011

\section{References}

1. Diabetes Epidemiology Research International Mortality Study Group: International evaluation of cause-specific mortality and IDDM. Diabetes Care 1991, 14:55-60.

2. Tuomilehto J, Borch-Johnsen K, Molarius A, Fprsén T, Rastenyte D, Sarti C, Reunanen $A$ : Incidence of cardiovascular disease in type 1 (insulindependent) diabetic subjects with and without diabetic nephropathy in Finland. Diabetologia 1998, 41:784-790.

3. American Diabetes Association: Diabetic nephropathy. Diabetes Care 2002, 25:S85-89.

4. Mogensen $C E$, Keane WF, Bennett PH, Jerums G, Parving HH, Passa P, Steffes GE, Viberti G: Prevention of diabetic renal disease with special reference to microalbuminuria. Lancet 1995, 346:1080-1084.

5. Cooper ME: Pathogenesis, prevention, and treatment of diabetic nephropathy. Lancet 1998, 352:213-219.
6. Perkins BA, Ficociello LH, Ostrander BE, Silva KH, Weinberg J, Warran JH, Krolewsk AS: Microalbuminuria and the risk for early progressive renal function decline in type 1 diabetes. J Am Soc Nephrol 2007, 18:1353-1361.

7. Giunti S, Barit D, Cooper ME: Mechanisms of diabetic nephropathy: role of hypertension. Hypertension 2006, 48:519-526.

8. Writing team for the Diabetes control and complications trial/Epidemiology of diabetes interventions and complications research group: Sustained effect of intensive treatment of type 1 diabetes mellitus on development and progression of diabetic nephropathy. JAMA 2003, 290:2159-2167.

9. Gomes MB, Gonçalves MFR, Dorigo D, Silva Junior GR, Neves R: Prospective study of development of microalbuminuria and retinopathy in brazilian IDDM patients. Acta Diabetol 2000, 37:19-25.

10. Friedewald WT, Levy RI, Fredrickson DS: Estimation of the concentration of low-density lipoprotein cholesterol in plasma, without use of the preparative ultracentrifuge. Clin Chem 1972, 14:499-502.

11. North American association for the study of obesity and the National heart, lung and blood institute, National institute of health: The practical guide: identification, evaluation and treatment of overweight and obesity in adults.[http://www.nhlbi.nih.gov/guidelines/obesity/prctgde.htm].

12. Hovind $P$, Tarnow $L$, Rossing $P$, Jensen BR, Graae $M$, Torp I, Binder $C$, Paring $\mathrm{H}-\mathrm{H}$ : Predictors for the development of microalbuminuria and macroalbuminuria in patients with type 1 diabetes: inception cohort study. BMJ 2004, 328:1105-1108.

13. Chaturvedi N, Bandinelli S, Mangili R, Penno G, Rottiers RE, Fuller JH, EURODIAB prospective complications study group: Microalbuminuria in type 1 diabetes: rates, risk factors and glycemic threshold. Kidney Int 2001, 60:219-227

14. Stone ML, Craig ME, Mappstat AKC, Lee JW, Verge CF, Donaghue KC: Natural history and risk factors for microalbuminuria in adolescents with type 1 diabetes. A longitudinal study. Diabetes Care 2006, 29:2072-2077.

15. The Diabetes Control and Complications Trial Research Study Group (DCCT): The effect of intensive treatment of diabetes on the development and progression of long-term complications in insulin-dependent diabetes mellitus. N Engl J Med 1993, 329:977-986.

16. Mathiesen ER, Ronn B, Storm B, Foght H, Deckert T: The natural course of microalbuminuria in insulin-dependent diabetes: a 10-year prospective study. Diabet Med 1995, 12:482-487.

17. Rossing P, Hougaard P, Parving H-H: Risk factors for development of incipient and overt diabetic nephropathy in type 1 diabetic patients: A 10-year prospective observational study. Diabetes Care 2002, 25:859-864.

18. Coonrod BA, Ellis D, Becker DJ, Bunker CH, Kelsey SF, Lloyd CE, Drash AL, Kuller LH, Orchard TJ: Predictors of microalbuminuria in individuals with IDDM.Pittsburgh Epidemiology of Diabetes Complications Study. Diabetes Care 1993, 16:1376-1383.

19. Tolonen N, Forsblom C, Thorn L, Waden J, Rosengard-Barlund M, Saraheimo M, Heikkila O, Pettersson-Fernholm K, Taskinen MR, FinnDiane Study Group: Relationship between lipid profiles and kidney function in patients with type 1 diabetes. Diabetologia 2008, 51:12-20.

20. Thomas MC, Rosengard-Barlund M, Mills W, Ronnback M, Thomas S, Forsblom C, Cooper ME, Taskinen MR, Viberti G, Per-Henrik Groop: Serum lipids and the progression of nephropathy in type 1 diabetes. Diabetes Care 2006, 29:317-322.

21. Roglic G, Colhoun HM, Stevens LK, Lemkes HH, Manes C, Fuller JH: Parental history of hypertension and parental history of diabetes and microvascular complications in insulin dependent diabetes mellitus: the EURODIAB complications study. Diabet Med 1998, 15:418-426.

22. Schalkwijk CG, Poland DCW, Dijk WV, Kok A, Emeis JJ, Drager AM, Doni A Van Hinsberg WWM, Stehouwer CDA: Plasma concentration of C-reactive protein is increased in type 1 diabetic patients without clinical macroangiopathy and correlates with markers of endothelial dysfunction: evidence for chronic inflammation. Diabetologia 1999, 42:351-357.

23. Gross $\mathrm{J}$, de Azevedo MJ, Silveiro SP, Canani LH, Caramori ML, Zelmanovitz T: Diabetic nephropathy: diagnosis, prevention, and treatment. Diabetes Care 2005, 28:164-176.

24. Kilpatrick ES, Rigby AS, Atkin SL: Insulin resistance, the metabolic syndrome, and complication risk in type 1 diabetes. Diabetes Care 2007, 30:707-712.

25. Purnell JQ, Hokanson JE, Marcovina SM, Steffes MW, Cleary PA, Brunzell JD: Effect of excessive weight-gain with intensive therapy of type 1 
diabetes on lipid levels and blood pressure: results from the DCCT. Diabetes Control and Complications Trial. JAMA 1998, 280:140-146.

26. Barone B, Rodacki M, Zajdenverg L, Almeida MH, Cabizuca CA, Barreto D, de Araújo LF, Kupfer R, Milech A, Oliveira JE: Family history of type 2 diabetes is increased in patients with type 1 diabetes. Diabetes Res Clin Pract 2008, 82:e1-4.

27. Gabbay MAL, Gomes MB, Pires AC, Dib SA: Prevalence and trends of metabolic syndrome in type 1 diabetes according to duration of the disease. Diabetes 2005, 54(Suppl 1):A176.

28. Orchard TJ, Chang YF, Ferrell RE, Petro N, Ellis DE: Nephropathy in type 1 diabetes: a manifestation of insulin resistance and multiple genetic susceptibilities? Kidney Int 2002, 62:963-970.

29. Sibley SD, Boer IH, Steffes MW, Brunzell JD: The diabetes control and complications trial/Epidemiology of diabetes interventions and complications (DCCT/EDIC) research study Group. Intra-abdominal fat and elevated urine albumin excretion in men with type 1 diabetes. Diabetes Care 2007, 30:1898-1900.

30. de Boer IH, Sibley SD, Kestenbaum B, Sampson JN, Young B, Cleary PA, Steffes MW, Weiss NS, Brunzell JD, Diabetes Control and Complications Trial/Epidemiology of Diabetes Interventions and Complications Study Research Group: Central obesity, incident microalbuminuria, and change in creatinine clearance in the Epidemiology of Diabetes Interventions and Complications Study. J Am Soc Nephrol 2007, 18:235-243.

31. Penno G, Miccoli R, Pucci L, Lucchesi D, Bandinelli S, Fortino C: Metabolic syndrome and nephropathy in type 1 diabetes: the Italian cohort of the EURODIAB IDDM complications study. Diabetes 2005, 54:A-211.

32. Thorn LM, Forsblom C, Fagerudd J, Thomas MC, Pettersson-Fernholm K, Saraheimo M, Wadén J, Rönnback M, Rosengård-Bärlund M, Björkesten CG, Taskinen MR, Groop PH, FinnDiane Study Group: Metabolic syndrome in type 1 diabetes. Association with diabetic nephropathy and glycemic control (the FinnDiane study). Diabetes Care 2005, 28:2019-2024.

33. Castro SH, Neto HCCF, Gomes MB: Association of post-prandial hyperglycemia with in vitro LDL oxidation in non-smoking patients with type 1 diabetes- A cross-sectional study. Rev Diabet Stud 2005, 2:157-164

34. Gomes MB, Piccirillo LJ, Nogueira VG, Matos HJ: Acute-phase proteins among patients with type 1 diabetes. Diabetes Metab 2003, 29:405-411.

35. Molitch ME, Rupp D, Carnethon M: Higher levels of HDL cholesterol are associated with a decreased likelihood of albuminuria in patients with long-standing type 1 diabetes. Diabetes Care 2006, 29:78-82.

36. Perségol $L$, Foissac $M$, Lagrost $L$, Athias $A$, Gambert $P$, Vergès $B$, Duvillard $L$ : $\mathrm{HDL}$ particles from type 1 diabetic patients are unable to reverse the inhibitory effect of oxidized LDL on endothelium-dependent vasorelaxation. Diabetologia 2007, 50:2384-2387.

37. Tuomilehto J, Borch-Johnsen K, Molarius A, Forsem T, Rastenyte D, Sarti C, Reunanen A: Incidence of cardiovascular disease in type 1 (insulindependent) diabetic subjects with and without diabetic nephropathy in Finland. Diabetologia 1998, 41:784-790.

38. Krolewski AS, Warram JTT, Christlieb R: Hypercholesterolemia.A determinant of renal function loss and death in IDDM patients with nephropathy. Kidney Int 1994, 45:S125-131.

39. Chatuverdi N, Fuller JH, Taskinen MR: Differing associations of lipid and lipoprotein disturbances with the macrovascular and microvascular complications in type I diabetes. Diabetes Care 2001, 24:2071-2077.

40. Perkins BA, Ficociello LH, Silva KH, Finkelstein DM, Warram JH, Krolewski AS: Regression of microalbuminuria in type 1 diabetes. N Engl J Med 2003, 348:2285-2293.

41. Parra FC, Amado RC, Lambertucci JR, Rocha J, Antunes CM, Pena SDJ: Color and genomic ancestry in Brazilians. Proceedings of the National Academy of Sciences of the United States of America 2003, 100:177-182.

doi:10.1186/1758-5996-3-21

Cite this article as: Cobas et al:: Progression to microalbuminuria in patients with type 1 diabetes: a seven-year prospective study. Diabetology \& Metabolic Syndrome 2011 3:21.

\section{Submit your next manuscript to BioMed Central and take full advantage of:}

- Convenient online submission

- Thorough peer review

- No space constraints or color figure charges

- Immediate publication on acceptance

- Inclusion in PubMed, CAS, Scopus and Google Scholar

- Research which is freely available for redistribution

Submit your manuscript at www.biomedcentral.com/submit 